\title{
Metamedica in de basisopleiding geneeskunde
}

\author{
W.P.J. van Oosterhout • J.A. Dekker
}

Samenvatting Inleiding: Onderwijs in metamedische aspecten is in het afgelopen decennium in de medische curricula geïmplementeerd op basis van het zogenaamde Calgary-model. Ethiek en recht, multiculturaliteit en kennis over het gezondheidszorgstelsel en van de administratieve

aspecten van het arts-zijn komen aan bod in de opleiding.

Methode: Een enquête is uitgevoerd onder ruim 4000 studentleden van de KNMG in opdracht van het KNMG Studentenplatform. Onderzocht werd of studenten geneeskunde deze metamedische aspecten belangrijk vinden en of zij tevreden zijn met de aandacht die hieraan wordt besteed in de basisopleiding.

Resultaten: Uit dit onderzoek blijkt dat ruim 95\% van de respondenten waarde hecht aan de ethische, juridische en multiculturele aspecten van het arts-zijn. Daarnaast vindt respectievelijk $95 \%$ en $86 \%$ van de ondervraagden het belangrijk kennis over het gezondheidszorgstelsel en over administratieve aspecten op te doen. In schril contrast hiermee staat de tevredenheid over de aandacht voor deze zogenoemde metamedische onderwerpen in het curriculum. Van de studenten geeft $86 \%$ aan de aandacht voor de ethische aspecten voldoende te vinden, terwijl slechts $63 \%$ vindt dat genoeg onderwijs wordt besteed aan de juridische aspecten. Minder tevreden zijn de ondervraagden over de overige metamedische aspecten: respectievelijk $56 \%, 17 \%$ en $48 \%$ van de respondenten is tevreden over de aandacht voor multiculturaliteit, gezondheidszorgstelsel en administratieve aspecten.

Discussie en conclusie: Omdat kennis van metamedica leidt tot competentieverbetering en noodzakelijk is voor het goed functioneren van een dokter, pleit het KNMG Studentenplatform voor meer aandacht voor metamedische aspecten in de basisopleiding geneeskunde. Het Studentenplatform ziet daarbij een rol weggelegd voor de medische faculteiten. (Oosterhout WPJ van, Dekker JA. Metamedica in de basisopleiding geneeskunde. Tijdschrift voor Medisch Onderwijs 2007;26(3):128-134.)

\section{Inleiding}

Studenten geneeskunde worden in de basisopleiding opgeleid tot klinisch werkzame artsen, die dagelijks medische hulpvragen beantwoorden. Van oudsher komen in de basisopleiding de anatomie, de fysiologie, de pathofysiologie en de farmacotherapie van vele ziektebeelden aan de orde. Daarnaast is de medicus practicus echter werkzaam in een groter raamwerk, waarbinnen de hulpverlening plaatsvindt. Eveneens is het voor de arts van vandaag van belang voldoende kennis te hebben van de ethische, juridische en culturele aspecten die van belang zijn binnen de hulpverlening, alsmede over goede communicatieve vaardigheden te beschikken. Deze aspecten worden ook wel 'metamedica' genoemd en zijn inherent aan competentiegericht leren. Het competentiegericht leren is in het afgelopen decennium door onderwijsvernieuwingen in de medische curricula geïmplementeerd op basis van het zogeheten Calgary-model. ${ }^{1}$ Dit gebeurde zowel als antwoord op een maatschappelijke vraag, als op advies van de Visitatiecommissie voor de Opleiding Geneeskunde. ${ }^{2}$ Arts worden omvat namelijk uitdrukkelijk meer dan het opdoen van medische kennis en kunde en het leren deze in praktijk te brengen; het is eveneens een vormingsproces in meerdere, specifieke rollen én in het ontwikkelen van een professionele 
zorgverlenerattitude en bijbehorende beroepsethiek. ${ }^{3}$ Patiënten zijn mondiger dan vroeger, wat enerzijds leidt tot een meer gelijkwaardige arts-patiënt relatie en anderzijds tot een groei in het aantal tuchtrechtelijke en civielrechtelijke procedures. Deze ontwikkeling versterkt de behoefte aan morele en wetenschappelijke vorming van de studenten, vroeg in het curriculum. In deze behoefte wordt onder andere voorzien door de medische professie tijdens de basisopleiding vanuit ethisch, juridisch en cultureel perspectief te bezien.

Zoals eerder genoemd, is in de afgelopen jaren meer aandacht voor de metamedica gekomen in de basisopleiding. Het doel van dit onderzoek is te achterhalen in hoeverre studenten waarde hechten aan deze aspecten en hoe de aandacht voor deze aspecten in het medisch curriculum kwantitatief door studenten geneeskunde wordt beoordeeld. Hieruit volgt de concretere probleemstelling van dit onderzoek. Hoe is de balans tussen hoeveelheid aandacht die aan de metamedica wordt besteed, de beoordeling daarvan door studenten geneeskunde en het belang dat zij aan deze aspecten toekennen?

\section{Methode}

Om de huidige stand van zaken omtrent de metamedica in de opleiding te inventariseren, zijn de studiegidsen van de acht faculteiten geneeskunde in Nederland geraadpleegd. Daarnaast is de rapportage van de meest recente, in 2003-2004 uitgevoerde visitatie van de medische opleidingen als bron gebruikt. ${ }^{4}$ Hieruit werden de benodigde gegevens wat betreft curriculumopbouw en -onderwerpen gedistilleerd.

Om de mening van studenten te achterhalen is gebruik gemaakt van de resultaten van de in begin 2006 uitgevoerde elektronische enquête van het KNMG Studentenplatform ${ }^{1}$ onder alle studentleden van de KNMG. In deze grootschalige, digitale enquête werd over verschillende relevante onderwerpen de mening van de 4035 studentleden van de KNMG gevraagd. Eerdere gesprekken met studentvertegenwoordigers van de diverse faculteiten droegen bij aan de keuze voor de bevraagde

\footnotetext{
${ }^{1}$ Het KNMG Studentenplatform is in 1996 opgericht als zelfstandig landelijk overlegorgaan. Het platform behartigt de belangen van studenten geneeskunde in Nederland en houdt zich bezig met de maatschappelijke aspecten van onderwerpen die studenten geneeskunde en coassistenten in heel Nederland aangaan. Standpunten worden onder andere gebaseerd op de resultaten van het jaarlijks uitgevoerde Studentenpanel, een elektronische enquête onder alle studentleden van de KNMG. Op basis van deze uitkomsten zet het platform zaken zowel binnen als buiten de KNMG op de kaart. Ook wil het platform aandacht vragen voor landelijke problemen en is daarom terughoudend

met het opsplitsen van onderzoeksresultaten per faculteit.
}

onderwerpen. Eén van de onderwerpen betrof de aandacht voor nietmedische aspecten binnen de basisopleiding en in hoeverre de aandacht voor deze aspecten voldoende wordt bevonden. De totale respons betrof 1858 (responspercentage 46\%), waarvan $72 \%$ vrouw. Van de respondenten bevond $52 \%$ zich in de pre-klinische fase van de opleiding (zie tabel 1). De responspercentages zijn gelijkelijk verdeeld over de verschillende faculteiten (zie tabel 2). Om deze resultaten vervolgens te kunnen vergelijken met buitenlandse ervaringen werd een literatuurstudie verricht.

\section{Resultaten}

Juridische en ethische aspecten

In het kader van de wetenschappelijke vorming komen de juridische en ethische aspecten binnen de medische sector op alle faculteiten in verschillende onderwijsvormen aan bod. Deze aspecten worden conform de eindtermen van het Raamplan behandeld en tot tevredenheid van de Visitatiecommissie getoetst. Interfacultair bestaan, zowel kwantitatief als kwalitatief, verschillen (zie tabel $3)$.

Uit de resultaten van het Studentenpanel blijkt dat de overgrote meerderheid van de ondervraagden waarde hecht aan kennis over het gezondheidsrecht $(96 \%)$ en medische ethiek (97\%). 86\% van de geënquêteerden is van mening dat er voldoende aandacht is voor medische ethiek. Wat betreft gezondheidsrecht zijn de meningen verdeeld. Interfacultaire verschillen bestaan, waarbij $63 \%$ van alle respondenten aangeeft dat voldoende aandacht wordt besteed aan gezondheidsrecht. Recht en ethiek worden vaak gezamenlijk behandeld. Het belang van gescheiden aandacht voor recht en ethiek komt echter naar voren in Amerikaans onderzoek. Morele en juridische legitimiteit zijn niet onderling uitwisselbaar. Een medische beslissing kent immers verschillende aspecten: een technisch besluit (behandeloptie) heeft een

Tabel 1 Kenmerken respondenten en studenten geneeskunde.

\begin{tabular}{lrrrr}
\hline & \multicolumn{2}{c}{ Respondenten } & \multicolumn{2}{c}{ Studenten geneeskunde1 } \\
& N & $\%$ & N & $\%$ \\
\hline Geslacht & & & & 35 \\
Man & 524 & 28 & 5.794 & 65 \\
Vrouw & 1332 & 72 & 10.730 & 100 \\
Onbekend & 2 & 0 & & \\
Totaal & 1858 & 100 & 16.524 & \\
Studiefase & & & & \\
Preklinisch & 963 & 52 & & \\
Klinisch & 895 & 48 & & \\
TBron: VSNU. & & & &
\end{tabular}




\begin{tabular}{lrrrr}
\hline & N & Respondenten & \multicolumn{2}{c}{ Studenten geneeskundel } \\
AMC & $\%$ & 12 & 2120 \\
VUmc & 219 & 9 & 2089 & 13 \\
LUMC & 170 & 10 & 1911 & 13 \\
Erasmus MC & 194 & 13 & 2295 & 12 \\
UMCU & 232 & 15 & 2047 & 12 \\
UMC St. Radboud & 279 & 15 & 1912 & 12 \\
AZM & 269 & 11 & 1819 & 11 \\
UMCG & 212 & 15 & 2331 & 12 \\
Totaal & 283 & $100 \%$ & 16524 & $100 \%$ \\
\hline
\end{tabular}

IBron: VSNU.

morele component (is de beslissing ethisch verantwoord?) en een juridische component (is de beslissing juridisch verdedigbaar?). ${ }^{5}$ Patiënten zijn mondiger en kritischer geworden. Het traditionele gezag van de arts is afgenomen. Deze ontwikkelingen dragen eraan bij dat de juridische componenten van de medische beslissing steeds belangrijker worden en ook juridische interventies meer dan vroeger voorkomen.

\section{Multiculturaliteit}

Kennis van culturele verschillen in de gezondheidszorg en ziektepresentatie wordt eveneens op alle faculteiten in verschillende vormen overgedragen. Zowel in blok-, lijnals keuzeonderwijs is naar tevredenheid van de Visitatiecommissie minimaal volgens de eindtermen van het Raamplan aandacht over onder andere de rol en invloed van culturele diversiteit en interculturaliteit. Echter, niet overal is ruimte voor reflectie en beschouwing van het eigen handelen (zie tabel 3$){ }^{4}$

Vierennegentig procent van de geënquêteerden hecht waarde aan kennis over multiculturaliteit en acht deze vaardigheden van belang voor het functioneren van een goede dokter. Dit is in overeenstemming met resultaten van Amerikaans en Engels onderzoek, waarin naar voren komt dat studenten geneeskunde waarde hechten aan kennis over multiculturaliteit en communicatieve vaardigheden. ${ }^{6-7}$ Uit het panel blijkt dat $56 \%$ van de respondenten de aandacht voor multiculturaliteit in het curriculum voldoende vindt.

\section{Gezondheidszorgstelsel en administratieve aspecten}

Aan het Nederlandse gezondheidszorgsysteem wordt op het merendeel van de medische faculteiten geen expliciete aandacht geschonken. Enkele faculteiten behandelen dit thema; soms wordt het in blokonderwijs maar veelal in de vorm van keuzeonderwijs aangeboden. Wel wordt overal via buitenlandse stages (en in keuzeonderwijs) ruimte gegeven andere, buitenlandse zorgsystemen te leren kennen (zie tabel 3). ${ }^{5}$

Respectievelijk $95 \%$ en $86 \%$ van de geënquêteerden geeft aan waarde te hechten aan onderwijs over het gezondheidszorgstelsel en kennis over administratieve aspecten van het arts-zijn. Uit literatuuronderzoek blijkt dat de vraag naar aandacht voor deze aspecten ook buiten Europa bestaat. In de Verenigde Staten bijvoorbeeld is onderzoek gedaan naar het effect van intra-curriculaire aandacht voor het gezondheidszorgstelsel. Hieruit blijkt dat $96 \%$ van de ondervraagde studenten meer kennis hierover wil en dat de kennis aangeboden zou moeten worden in het medisch curriculum. ${ }^{8}$

Slechts $17 \%$ vindt dat de administratieve aspecten voldoende aan de orde komen en $48 \%$ vindt dat met betrekking tot het gezondheidszorgstelsel.

Dat kennis over de gezondheidszorg van belang is voor het goed functioneren als arts, lijkt triviaal. Amerikaans onderzoek toont dat leermomenten omtrent gezondheidszorgbeleid in het medisch curriculum tot een attitudeverandering van de toekomstig artsen kunnen leiden waardoor zij onder andere beter samenwerken met andere werkers in de gezondheidszorg. ${ }^{9}$

\section{Discussie en conclusie}

Uit dit door het KNMG Studentenplatform uitgevoerde onderzoek is gebleken dat studenten geneeskunde de onderzochte metamedische aspecten belangrijk vinden voor het functioneren van een goede dokter. In schril contrast hiermee staat het hoge percentage ondervraagden dat aangeeft niet tevreden te zijn met de aandacht die momenteel aan deze belangrijke aspecten geschonken wordt in de basisopleiding. Aangezien slechts KNMG studentleden zijn benaderd, zou de representativiteit van het onderzoek onderwerp van discussie kunnen zijn. Het KNMG Studentenplatform is zich bewust van de beperkingen van een dergelijk onderzoek maar beschouwt de 
Tabel 3 Mening van respondenten over het belang van de inhoud en de mate van aandacht voor de diverse niet-medische aspecten.

\begin{tabular}{lrrr}
\hline Aspect & Aandacht* & Vindt inhoud van belang & Vindt aandacht in curriculum voldoende \\
\hline Juridische aspecten & + & $96 \%$ & $63 \%$ \\
Ethische aspecten & + & $97 \%$ & $86 \%$ \\
Multiculturaliteit & + & $94 \%$ & $56 \%$ \\
Gezondheidszorg & $+/-$ & $95 \%$ & $48 \%$ \\
Administratieve aspecten & $+/-$ & $86 \%$ & $17 \%$ \\
\hline
\end{tabular}

$*+=$ Expliciete aandacht in het curriculum middels verplichte en keuzevakken op alle faculteiten.

$+/-=$ Minder expliciete aandacht voor dit aspect binnen het curriculum op alle faculteiten.

resultaten, gezien het responspercentage, de verdeling van de respondenten over de faculteiten en de geslachtsverdeling, als een betrouwbare afspiegeling van de populatie Nederlandse studenten geneeskunde.

Met betrekking tot de ethische aspecten zijn studenten tevreden over de aandacht hiervoor in het curriculum, wat suggereert dat zij menen met de tijdens de opleiding opgedane kennis ethische vraagstukken op professionele wijze te kunnen benaderen.

Het feit dat slechts $63 \%$ van de ondervraagden aangeeft dat zij de aandacht voor de juridische aspecten voldoende vindt, doet de vraag rijzen of studenten geneeskunde genoeg juridische kennis bezitten. Kunnen zij wel op een professionele manier omgaan met het gezondheidsrecht en de concrete invulling daarvan, onder andere de WGBO en de Wet BIG, zoals dat van hen mag worden verlangd?

Uit dit onderzoek blijkt ook dat slechts iets meer dan de helft van het aantal studenten aangeeft tevreden te zijn met de aandacht voor multiculturaliteit in het curriculum. Een groot aantal studenten voelt zich blijkbaar niet voldoende voorbereid op dit gebied. Dit resultaat baart het KNMG Studentenplatform zorgen, aangezien juist in de huidige samenleving multiculturaliteit een gegeven is. In het medisch curriculum zou hieraan dan ook meer aandacht moeten worden besteed.

Met betrekking tot de kennis over het gezondheidszorgstelsel en de administratieve aspecten zijn de resultaten van dit onderzoek schrikbarend. Ruim de helft van de ondervraagden geeft aan dat zij de aandacht voor kennis over het gezondheidszorgstelsel niet voldoende vindt in de basisopleiding.

Ruim tachtig procent heeft eenzelfde mening over de aandacht voor administratieve aspecten, terwijl beide thema's door studenten van belang worden gevonden voor het functioneren van een goede dokter.

De onderzochte aspecten maken deel uit van het zogenaamde Calgary-model, waarin acht professionele competenties van een goede dokter worden beschreven. Uit enkele aangehaalde onderzoeken is gebleken dat aandacht voor de onderzochte metamedische aspecten in de medische basisopleiding kan leiden tot een vermindering van het aantal problemen dat door competentiegebrek ontstaat. Dergelijke problemen kunnen immers ontstaan door onvoldoende juridische en ethische visie, alsook door ontoereikende communicatieve en administratieve vaardigheden. Meer aandacht aan deze aspecten in de basisopleiding kan leiden tot verbetering van deze vaardigheden. Op termijn is hierdoor wellicht ook een vermindering van het aantal claims en tuchtrechtelijke procedures te verwachten. Bovendien komt meer aandacht voor multiculturaliteit en het zorgstelsel ten goede aan de algemene professionele attitude.

Het KNMG Studentenplatform ziet dan ook graag dat in de basisopleiding geneeskunde meer aandacht wordt besteed aan de juridische, multiculturele en administratieve aspecten die bestaan binnen het raamwerk van professionele gezondheidszorg dan nu het geval is en dat meer kennisoverdracht plaatsvindt met betrekking tot het gezondheidszorgstelsel. Hierin is een belangrijke rol weggelegd voor de faculteiten geneeskunde in den lande.

\section{Dankwoord}

De auteurs willen mw. drs. G.M. de Jong en mw. drs. I. M. Tjiam, voormalig leden van het KNMG Studentenplatform, bedanken voor hun inbreng.

Belangenconflict: geen gemeld.

Financiële ondersteuning: geen gemeld.

\section{Summary}

Introduction: Metamedical aspects of medicine have been taught to undergrate medical students in accordance with the so-called Calgary model during the past decade. Metamedical courses cover ethics and law, multiculturalism, the organisation of health care and administrative aspects of medical practice.

Method: The Student Platform of the Royal Dutch Medical Association commissioned a questionnaire survey among 4000 student-members of the Royal Dutch Medical Association to investigate whether medical students value metamedical aspects as part of their training and whether they are satisfied with the coverage of these subjects.

Results: Over $95 \%$ of respondents considered ethical, legal and multicultural aspects of medical practice to be of importance and $95 \%$ and $86 \%$ of respondents thought it was important for them to learn about the organisation of health care and administrative aspects of medical practice, respectively. This is in sharp contrast to respondents' satisfaction with the actual coverage of these 
subjects in the curriculum. While $68 \%$ of respondents considered the attention for ethical issues to be sufficient, only $63 \%$ were satisfied with the teaching of legal issues, and $56 \%, 17 \%$ and $48 \%$ expressed satisfaction with the amount of attention for multiculturalism, organisation of health care, and administrative matters, respectively.

Discussion and conclusion: Because knowledge of metamedical aspects enhances competence and is a prerequisite for the proper functioning of doctors, the Royal Dutch Medical Association strongly advocates increased attention for metamedical subjects in undergraduate medical education. The Student Platform thinks that the Dutch medical faculties have a major role to play in this regard. (Van Oosterhout WPJ, Dekker JA. Metamedical topics for undergraduate medical education. Dutch Journal of Medical Education 2007;26(3):128-134.)

\section{Literatuur}

Kurtz S, Heaton CJ. Teaching and assessing in-formation giving skills in communication curriculum. In: Rotham A, Cohen R, editors. Proceeding sixth Ottawa conference on medical education. Toronto, Canada: University of Toronto Printing; 1994. p. 524-6.

Onderwijsvisitatie Geneeskunde en Gezondheidswetenschappen. Utrecht: VSNU; 1997.

Essed G. Morele vorming van medische studenten in en door de klinische praktijk. Tijdschrift voor Gezondheid en Ethiek 2005;15(4);94-7.

Onderwijsvisitatie Geneeskunde. Visitatierapport opleiding geneeskunde. 2004. [geciteerd 15-0507] Beschikbaar op: www.qanu.nl/comasy/uploadedfiles/ GeneeskundeRapportwebsite.pdf

Olick RS. It's ethical, but is it legal? Teaching ethics and law in the medical school curriculum. Anat Rec 2001;265(1):5-9.

Teutsch C. Patient-doctor communication. Med Clin North Am 2003;87(5):1115-45.

Dogra N, Karnik N. Teaching cultural diversity to medical students. Med Teach 2004;26(8):677-80.

Agrawal JR, Huebner J, Hedgecock J, Sehgal AR, Jung P, Simon SR. Medical students' knowledge of the U.S. health care system and their preference for curricular change: a national survey. Acad Med 2005;80(5);484-8.

Riegelman R. Commentary: health systems and health policy: a curriculum for all medical students. Acad Med 2006;81 (4);391-2. 